\title{
LA NOCIÓN DE CARGA PÚBLICA Y SU FUNCIÓN EN LA JURISPRUDENCIA DEL TRIBUNAL CONSTITUCIONAL CHILENO
}

\author{
THE NOTION OF PUBLIC BURDEN AND ITS FUNCTION IN THE \\ CHILEAN CONSTITUTIONAL COURT'S CASE LAW
}

\author{
Viviana Ponce de León Solís*
}

\begin{abstract}
RESUMEN: Este artículo estudia los criterios que el Tribunal Constitucional chileno ha desarrollado en los últimos años para enjuiciar la legitimidad de la imposición de cargas públicas. El propósito de dicho estudio es determinar cuál es el significado autónomo y diferenciado de la noción de carga pública, así como su función teórica en la argumentación constitucional. Para tal efecto, comienza con una revisión de la discusión en la doctrina comparada y nacional sobre el tópico, a objeto de identificar los principales aspectos controvertidos. Luego, se sistematizan y analizan los pronunciamientos del Tribunal, a fin de precisar cuál es el concepto de carga pública que este maneja y cuál es el sentido útil que da a esta idea.
\end{abstract}

Palabras clave: Cargas públicas, Cargas reales, Cargas personales, Razonabilidad, Proporcionalidad.

ABSTRACT: This paper studies the criteria developed by the Chilean Constitutional Court over the last few years, to judge the legitimacy of the imposition of public burdens. The purpose of such study is to determine what is the autonomous and differentiated meaning of the notion of public burden, as well as its theoretical function in constitutional argumentation. To that effect, it starts by reviewing comparative and national scholarly discussion on the topic, in order to identify the key controversial issues. Then, it systematizes and analyzes the Court's case law, to elucidate what is the concept of public burdens it handles and what is the useful sense it gives to this idea.

Key words: Public burdens, Real burdens, Personal burdens, Reasonableness, Proportionality.

\section{INTRODUCCIÓN}

Con el término carga pública se suele aludir a ciertas formas de contribución de los individuos a la supervivencia y al cumplimiento de los fines de la organización política, que pueden representar para aquellos un sacrificio en su patrimonio o libertad. Así, históricamente han recibido esta denominación figuras como las limitaciones al dominio, la expropiación, los tributos, el servicio militar obligatorio, las funciones electorales, el deber de declarar como testigo, el servicio del abogado de turno, la detención y la prisión preventiva,

\footnotetext{
* Abogada. Profesora de Derecho Constitucional de la Escuela de Derecho de Antofagasta, de la Facultad de Ciencias Jurídicas de la Universidad Católica del Norte. Candidata a doctora en derecho por la Pontificia Universidad Católica de Valparaíso y becaria CONICYT de Doctorado Nacional, concurso 2012. Dirección Postal: Angamos 0610, Antofagasta. Correo electrónico: vponcedeleon@ucn.cl.
} 
entre otras. Ahora bien, pese a estos ejemplos de uniformidad denotativa, y a que en la actualidad este término goza de reconocimiento en diversos ordenamientos -ya mediante su incorporación en el respectivo texto fundamental, ya mediante su recepción en el lenguaje de los jueces y la doctrina-, sus deslindes conceptuales son difusos. De hecho, si se observa la evolución que ha experimentado su uso en el último siglo, puede apreciarse una clara tendencia al desplazamiento conceptual, desde la idea de contribución antes referida, hacia las ideas de daño, privación, limitación o deber.

En este contexto, resulta curiosa la escasa y asistemática atención que le ha dispensado la doctrina constitucional contemporánea. Especialmente si se consideran las implicancias del manejo conceptual de las cargas públicas en la extensión de las libertades y derechos de los particulares, así como en el ejercicio del poder estatal. Quizás ello se deba a que se trata de una categoría dogmática que goza de una popularidad considerablemente menor que la de derechos fundamentales. Tal vez sea consecuencia de su difundida equiparación a la idea de desventaja o daño. $\mathrm{O}$, incluso, se podría atribuir a las dificultades que conlleva articular un concepto unitario comprensivo de supuestos tan disímiles entre sí, como el impuesto y el control de identidad. En todo caso, cualquiera sea el motivo de este desinterés, existen muy buenas razones para profundizar en el análisis de este tópico.

Efectivamente, del alcance que se dé a la noción de carga pública depende el propio concepto de Estado y la comprensión del vínculo que une a este con la sociedad. Para entender este aserto es necesario recordar que el cumplimiento de las tareas propias del Estado, la garantía de la paz interna y de la libertad humana, es imposible sin algún grado de contribución por parte de los individuos. Tal premisa es, con seguridad, por todos conocida y, probablemente, nadie la pondría en cuestión.

Pues bien, el problema que aborda esta investigación se relaciona, precisamente, con el vaciamiento de significado que ha experimentado esa premisa en el último tiempo y con la mutación del sentido de aquello que se concibe como legítimamente exigible por la comunidad al individuo. Si se llegase a considerar, como lo hacen algunas de las doctrinas más difundidas en la actualidad, que la imposición de cargas públicas deviene en ilícita por el hecho de causar daño o acarrear consecuencias desfavorables, entonces el Estado se verá forzado a destinar recursos públicos a su reparación, exigiendo, a su vez, nuevas contribuciones de los particulares. O quizás se vea forzado a establecer regímenes transitorios o a desaplicar su normativa, en beneficio los perjudicados, aun cuando su actuación persiga un fin de interés general. En fin, sin importar cuál sea la medida que se adopte al efecto, la consecuencia es la misma: un Estado que ve cada vez más reducidas sus posibilidades de servir al bien común.

Ante la existencia de una referencia explícita a las cargas públicas en el texto constitucional chileno y ante las crecientes alusiones a las mismas en la jurisprudencia del Tribunal Constitucional, este estudio pretende determinar cuál es el sentido que se atribuye a esta noción y cuál es la función teórica que esta desempeña en los pronunciamientos de la mentada judicatura. Para ello, se comienza por situar esta investigación en el marco de una discusión de alcance global y local acerca de la extensión de la idea de carga pública. A continuación, se sistematizan y someten a evaluación crítica los diversos criterios empleados 
por el Tribunal para legitimar la imposición de estas figuras, con el propósito de determinar cuál es su función propia en la argumentación constitucional.

Una primera conclusión que puede extraerse de este ejercicio es que, si bien no existe una definición jurisprudencial plenamente depurada de carga pública, en los fallos constitucionales existen ciertos elementos que pueden servir de base para su conceptualización. En segundo término, es posible observar que en torno a la noción de carga pública se articulan múltiples tests o exámenes -como el de razonabilidad, el de no arbitrariedad de las discriminaciones y el de proporcionalidad-, que se conjugan entre sí en variadas formas dependiendo de si la carga objeto de análisis incide en la libertad o en el patrimonio de los particulares. Por último, y en tercer lugar, a pesar del carácter neutral o meramente formal que suele atribuirse a estos tests, puede apreciarse que la noción de carga pública brinda una orientación sustantiva a su aplicación. La parte final de este artículo es destinada al desarrollo de estas reflexiones.

\section{ESTADO DE LA CUESTIÓN EN LA DOCTRINA COMPARADA}

En los ordenamientos occidentales pueden encontrarse dos modelos de recepción de la noción de carga pública: en virtud de su expresa incorporación en el texto constitucional o bien en virtud de su incorporación jurisprudencial y doctrinaria. Así, por ejemplo, en casos como los de Argentina (art. 16), Chipre (art. 24 n. 1), Francia (art. 40), Grecia (art. 4 n. 5), Honduras (art. 205), Hungría (art. 40), Nicaragua (art. 71), Noruega (art. 75), República Dominicana (art. 243) o Venezuela (art. 316), dicha noción se encuentra positivada en la constitución. En cambio, en los casos de Bélgica, Colombia, España, Estados Unidos y Holanda, su reconocimiento opera por la vía de su incorporación en el lenguaje de los jueces y la doctrina.

Independientemente de la fuente de incorporación de la noción de carga pública, en todos los sistemas mencionados esta opera como un elemento conciliador de intereses públicos y privados, en el ámbito de la actividad legítima del Estado. De ahí que las construcciones doctrinarias y jurisprudenciales orientadas a la protección de los derechos de los individuos frente a los efectos negativos derivados de la actividad estatal lícita tiendan a articularse en torno a la noción de carga pública. En Francia, Holanda y Bélgica cumple tal función el principio de igualdad ante las cargas públicas. Otro tanto ocurre en España con la teoría de la responsabilidad objetiva del Estado, uno de cuyos posibles fundamentos está dado por una desigual distribución de cargas públicas. Lo mismo sucede en Estados Unidos, donde se advierte una creciente vinculación entre la doctrina de las regulatory takings y el concepto de carga pública. En Alemania, por último, aunque no se emplea el término 'carga pública', se apela a la idea funcionalmente análoga de 'sacrificio', en aplicación de la teoría del sacrificio especial.

Con todo, puesto que esta clase de doctrinas puede terminar por inhibir actuaciones públicas necesarias y aun deseables, en la literatura sobre el tópico con insistencia una preocupación por acotar el sentido de la expresión carga pública. Tomo como primera ilustración de ello el trabajo de Michiel Tjepkema, a propósito de la notable proliferación de sentencias condenatorias contra el Estado, basadas en una lesión al principio de igualdad 
ante las cargas públicas en Holanda ${ }^{1}$. Ante este panorama, él insta a restringir el ámbito de aplicación de esta figura únicamente a aquellos casos en que el daño infligido pueda ser calificado como una verdadera carga pública, es decir daños que deba soportar un individuo como consecuencia de la acción deliberada de la autoridad estatal, que resultan necesaria e inevitablemente de actuaciones desplegadas para la consecución de un fin de interés general. En consonancia con esta idea, las actuaciones estatales idóneas para generar cargas públicas son aquellas en que existe una ponderación previa de los diversos intereses involucrados, como los actos administrativos, los reglamentos, las leyes e incluso los tratados internacionales ${ }^{2}$.

Una reflexión complementaria es desarrollada por Steven Lierman, con ocasión de la reciente recepción del principio en comento en la jurisprudencia belga. Para él, un sistema de responsabilidad íntegramente fundado en esta construcción resultaría inviable, toda vez que frustraría la acción estatal y entraría en conflicto con el interés general ${ }^{3}$. Comparte también la idea de delimitar la noción de carga pública, en términos similares a los expuestos en el párrafo anterior, entendiendo que una auténtica carga solo puede surgir de actos estatales legítimos, expedidos previa ponderación de los intereses públicos y privados implicados. Sin embargo, plantea la interrogante acerca de si esta noción, una vez acotada en la forma ya apuntada, se extendería a violaciones a la integridad física, a los riesgos propios de la actividad empresarial o a los riesgos inherentes a la vida en sociedad ${ }^{4}$.

Dentro de este mismo orden de ideas, aunque ahora en referencia a la excesiva amplitud del sistema español de responsabilidad objetiva de la Administración, Oriol Mir Puigpelat comenta: "La propia idea de carga, de sacrificio [...] se adapta mal a los daños ocasionados en forma incidental por la actividad administrativa, adecuándose mejor a los daños expropiatorios, aquellos que son provocados deliberadamente por el poder público por venir exigidos por el interés general, aquellos que constituyen un medio necesario para la consecución del fin público. Solo estos daños pueden ser considerados una carga, un sacrificio; los daños incidentales no pueden ser considerados una carga, un sacrificio, porque no vienen exigidos por la colectividad, por el interés general"5.

En Francia, país de origen la doctrina de la igualdad ante las cargas públicas, el término carga pública ha sido utilizado para englobar a la totalidad de las obligaciones que el poder público impone a los individuos para la satisfacción del interés general e inclusive cualquier daño ocasionado por las autoridades ${ }^{6}$. A pesar de ello, una serie de autores ${ }^{7}$ también concuerda en la necesidad de limitar su alcance únicamente a las sujeciones que el Estado deliberadamente impone a los particulares como mecanismo necesario para la consecución de un fin de interés público. Es de este modo que se llega igualmente a concluir

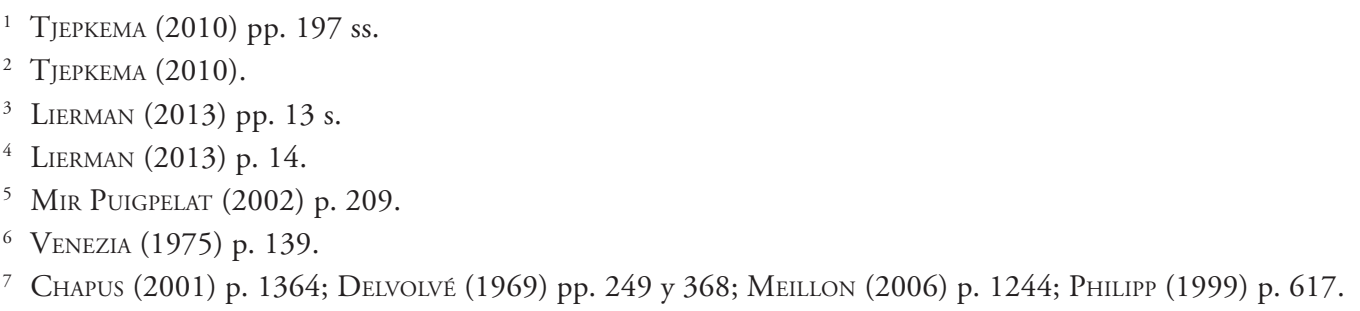


que solo ciertos actos estatales, emanados de determinados órganos y que persigan algunos fines en particular, pueden dar lugar a cargas públicas.

Una clase distinta de preocupaciones ha surgido a propósito de la reiterada asociación entre la quinta enmienda a la constitución de los EE.UU. y el concepto de carga pública. Ello, a partir de la lectura dada por el justice Hugo Black a la Quinta Enmienda a la Constitución norteamericana, según la cual esta tiene por objeto "impedir que el gobierno fuerce a ciertos individuos a soportar por sí solos cargas públicas que, en toda justicia y equidad, debieran ser soportadas por el público como un todo". Si bien, hasta el momento, el foco de atención se ha centrado predominantemente en el criterio distributivo orientador en la imposición de cargas públicas y en la intensidad o magnitud de sus efectos, comienzan a surgir inquietudes en un sentido distinto. En efecto, si las cargas públicas por definición benefician a todos, sirviendo sustancialmente a la consecución de intereses estatales legítimos ("substantially advance legitimate state interests" ${ }^{\prime \prime}$ ), ¿por qué sus costos deben ser indemnizados por el Estado, en lugar de ser soportados íntegramente por los particulares ${ }^{10}$ ?

En síntesis, las propuestas comparadas en orden a precisar el sentido de la noción de carga pública apuntan a calificar genuinamente como tal solo a aquellas entidades que satisfagan ciertos requisitos. El primero de ellos consiste en que solo pueden operar como fuente de cargas los actos de autoridad estatal lícitos o legítimos, que resulten de una adecuada ponderación de los diversos intereses involucrados. Surge de lo expuesto, entonces, que solo los actos legislativos y ciertos actos normativos de la Administración podrían dar lugar al nacimiento de cargas públicas. Y ello es así porque lo consustancial a estos actos es la ponderación en abstracto de los intereses públicos y privados concernidos. Es del caso subrayar, eso sí, que esta es una exigencia que cobra relevancia solo en aquellos ordenamientos en que no existen restricciones explícitas al establecimiento de cargas públicas. En el resto de los ordenamientos, habrá que estarse a lo que disponga el respectivo texto constitucional, el cual podría reconocer una única fuente legítima de cargas públicas -usualmente la ley-, tal como ocurre en el caso chileno.

En segundo lugar, el acto estatal que da origen a la carga debe perseguir la satisfacción de un fin de interés general. Precisamente en ese interés radica el fundamento mismo de la potestad del Estado para imponer cargas públicas y la gratuidad de estas. Es por esto que, pese a que la noción de carga pública alude a un complejo conjunto de fenómenos con expresiones locales prácticamente infinitas, es posible apreciar tipologías arquetípicas de cargas que invariablemente se vinculan con el interés general. Así es como, en distintos ordenamientos, se presentan tradicionalmente determinadas categorías de cargas que se vinculan directamente con la subsistencia y el funcionamiento de la organización política. A modo de ejemplo de dichas categorías se puede mencionar a aquellas cargas que se relacionan con la administración de justicia (declarar en juicio o servir como jurado), las que se conectan con la defensa de la soberanía nacional (el servicio militar, al menos en aquellos

8 "The Fifth Amendment's guarantee that private property shall not be taken for a public use without just compensation was designed to bar Government from forcing some people alone to bear public burdens which, in all fairness and justice, should be borne by the public as a whole". Cfr. Armstrongv. United States, 364 U.S. 40,49 (1960).

9 Agins v. City of Tiburon, 447 U.S. 255, 261-262 (1980).

10 Así, por ejemplo, en Gaba (2007); Ball y Reynolds (2006) pp. 1554-1559; Coletta (1990) pp. 346 ss. 
países en que es obligatorio), las que atañen al correcto desarrollo de los procesos electorales (actuar como vocal de mesa) o las que conciernen a la existencia y goce efectivo de bienes colectivos (la expropiación o las limitaciones al dominio), solo por mencionar algunas.

Como tercer y último requisito, la imposición de la carga debe constituir el medio necesario e ineludible para la consecución del fin de interés general que se pretende satisfacer, de manera que exista una relación de medio a fin entre aquella y este. Ahora, para precisar si se cumple este requisito, será necesario recurrir a dos conocidos cánones o parámetros para juzgar la constitucionalidad de las actuaciones estatales: el principio de razonabilidad y el principio de proporcionalidad ${ }^{11}$.

Resulta de todo lo expuesto que para calificar a un determinado fenómeno como de carga pública es necesario atender a su fuente y a su finalidad. Por lo tanto, las consecuencias o efectos económicos desfavorables que puedan derivar de ellas no alteran su naturaleza, ni ocasionan que devengan en ilícitas. Vistas de este modo las cargas públicas, puede afirmarse, constituyen una categoría conceptual claramente diferenciada de la de daños, que justamente atiende a los efectos que se siguen de una determinada conducta. Dentro de esta misma línea de pensamiento, una verdadera carga habría de ser susceptible de determinación ex ante, pues de lo contrario no sería posible predicar de ella su orientación, su predeterminación al interés común. En cambio un daño, siguiendo con este mismo razonamiento, por su propia naturaleza solo admite una determinación ex post, en atención a las consecuencias que sufre o experimenta un sujeto en concreto.

\section{ESTADO DE LA CUESTIÓN EN LA DOCTRINA NACIONAL}

A diferencia de lo que ocurre en la doctrina comparada, el punto de partida en la discusión acerca del sentido de la expresión carga pública en Chile está dado por su diferenciación con otras categorías dogmáticas. La cuestión surge debido a la alusión contenida en el artículo 19 No 20 de la Constitución a "la igual repartición de los tributos [...] y la igual repartición de las demás cargas públicas"12, así como a la referencia que se encuentra en el artículo 22 de la Constitución al "servicio militar y las demás cargas personales"13. Eso explica por qué la discusión local tiene como ejes centrales los siguientes puntos: (i) la conceptualización de las cargas públicas, en general; (ii) la distinción entre cargas reales y

\footnotetext{
11 En doctrina, no siempre resulta del todo clara la distinción entre uno y otro. Hay quienes consideran que pueden emplearse indistintamente los vocablos ponderación, proporcionalidad, razonabilidad o interdicción de la arbitrariedad, para referir a los mecanismos de resolución de colisiones de principios. Cfr. PRIETO (2007) p. 116. Otros, utilizan a un mismo tiempo los términos proporcionalidad y razonabilidad para aludir al control de la idoneidad, necesidad y proporcionalidad en sentido estricto de las afectaciones a los derechos fundamentales. Cfr. Cianciardo (2004). Sin embargo, algunos autores han advertido que aunque los principios de razonabilidad y de proporcionalidad se vinculan, no son lo mismo. Mientras que el primero involucra un análisis acerca de la legitimidad del fin que motiva una afectación de los derechos fundamentales, el segundo apunta a establecer si el medio empleado es el más adecuado para alcanzar ese fin. En ese sentido son entendidos estos principios en las páginas que siguen. Cfr. Martínez y Zúñiga (2011) pp. 201 s.; Bernal (2007) p. 695.

12 Énfasis añadido.

13 Énfasis añadido.
} 
cargas personales, según su objeto; y (iii) la relación que existe entre cargas públicas y tributos u otras figuras jurídicas.

En torno este punto, Enrique Evans de la Cuadra señalaba que son cargas públicas:

"todas las prestaciones de carácter personal y todas las obligaciones de carácter patrimonial que no sean jurídicamente tributos, que la ley impone a la generalidad de las personas para el cumplimiento de determinados fines, ética y jurídicamente lícitos, queridos por el legislador"14.

En esta clásica definición -que por lo demás ha sido adoptada en varias oportunidades por el Tribunal Constitucional ${ }^{15}$ - las cargas públicas son definidas por exclusión. De este modo, una carga es toda prestación, servicio u obligación que incida en la libertad o el patrimonio de un particular y satisfaga fines predeterminados por el legislador, que no sea tributo.

A su turno, Miguel Ángel Fernández considera que la relación que opera entre ambas figuras no es de exclusión, sino de género a especie. A partir de esta idea, el asunto en el que Fernández se concentra es en el de dilucidar cómo ellas se distinguen conceptualmente. Al efecto, él advierte que en virtud de la imposición de tributos tiene lugar un desplazamiento patrimonial o un traspaso de bienes desde el patrimonio del contribuyente, hacia el patrimonio estatal. Contrariamente, las cargas públicas no implican tal desplazamiento o traspaso patrimonial, sin perjuicio de poder incidir de modo diverso en la propiedad de los individuos ${ }^{16}$. La utilidad práctica que el autor asigna a la discriminación entre estas dos categorías estribaría en la diversa manera de fundamentar la aplicación de los principios de igualdad, proporcionalidad y justicia a cada una de ellas ${ }^{17}$.

Otro enfoque sobre el deslinde conceptual entre tributo y carga pública es desarrollado por Arturo Fermandois. De acuerdo con este autor, ella no hace más que recoger una costumbre y posee escasa importancia para el derecho constitucional ${ }^{18}$. Para sustentar esta afirmación, se apoya en la idea de que toda carga tiene valor pecuniario y, consiguientemente, naturaleza tributaria. Conforme a este razonamiento, solo podrían entenderse como cargas públicas 'puras' aquellas que consistan en servicios que no puedan valorarse pecuniariamente, por causas económicas o legales justificadas que determinen la ausencia de demanda por ellos ${ }^{19}$. El resto, vale decir, las cargas reales en general y las cargas personales que consistan en servicios susceptibles de apreciación dineraria, debe entenderse comprendido dentro de una más amplia y genérica concepción de los tributos.

Por su parte, Salvador Mohor concibe a las cargas públicas como exigencias impuestas unilateralmente por el Estado, destinadas a satisfacer finalidades superiores de bien público, que necesariamente suponen una afectación de derechos subjetivos. Bajo esta óptica,

14 Evans (1999) p. 285.

15 Roles Nos 790 (2007) c. 38; 1138 (2009) c. 44; 1141 (2009) c. $38 ; 1254$ (2009) c. 69.

16 FERnÁNdeZ (2000) p. 358.

17 Fernández (2000) p. 359.

18 Fermandois (2010) p. 127.

19 Fermandois (2010) p. 129. 
la expresión carga pública debe considerarse como sinónima de limitación ${ }^{20}$. Ahora bien, la equiparación puede resultar problemática, pues la idea de limitación suele asociarse a la de subsistencia de un derecho. En contraste, la idea de carga pública sí puede vincularse a ciertas hipótesis de extinción de un derecho, como ocurre en la expropiación por causa de utilidad pública. La clave para resolver esta aparente contradicción, según Mohor, estaría en admitir que si una limitación es tal cuando reduce la extensión de un derecho, debe seguir siéndolo cuando ese efecto reductivo se proyecta en la totalidad del derecho ${ }^{21}$. Por la vía de reconocer una mera diferencia de grado entre limitaciones y privaciones, es posible dar por establecida la indemnizabilidad de las primeras, en proporción al grado de afectación que ellas signifiquen para el respectivo derecho ${ }^{22}$.

Construcciones de esta naturaleza abundan en el debate académico nacional. De hecho, una serie de otros autores también ha afirmado la indemnizabilidad de ciertas cargas públicas $^{23}$, usualmente en conexión con la tesis de la responsabilidad objetiva del Estado, la teoría del sacrificio especial o la doctrina de las regulaciones expropiatorias. Esta conexión sugiere que los tribunales chilenos podrían fundar decisiones similares a las que resultarían de la aplicación de alguna de aquellas elaboraciones jurisprudenciales, pero ahora con sustento en la prohibición constitucional tributos manifiestamente desproporcionados e injus$\operatorname{tos}^{24}$ o en el principio de igualdad ante la ley ${ }^{25}$.

Con todo, Eduardo Aldunate llama a recordar que el actuar del Estado, en vistas al logro del bien común y a la satisfacción de las exigencias derivadas del principio de servicialidad, es imposible sino en virtud de "la posibilidad de una disminución imperativa y legítima de la esfera de nuestras libertades o nuestro patrimonio" ${ }^{26}$. Tal disminución puede, efectivamente, expresarse en una afectación en abstracto del contenido protector de un derecho -o limitaciones, en sentido técnico-, como ocurre en las limitaciones al dominio; pero puede también adoptar la forma de una afectación concreta del mismo, como en el caso de la expropiación o de la prisión preventiva ${ }^{27}$. Sin importar cuál sea la modalidad que asuma una carga, su legitimidad deriva de su orientación al bien común, de modo que no deviene en ilícita por el solo hecho de causar daño ${ }^{28}$.

A la luz del estado de la cuestión en la doctrina nacional, es posible afirmar que existen varios puntos de convergencia con la doctrina extranjera. En ambos casos existe coincidencia en estimar que una carga pública necesariamente debe tener su origen en un acto de autoridad estatal y que su imposición debe fundarse en un fin de interés común, predeterminado por dicha autoridad. Del mismo modo, aunque existen numerosas propuestas en

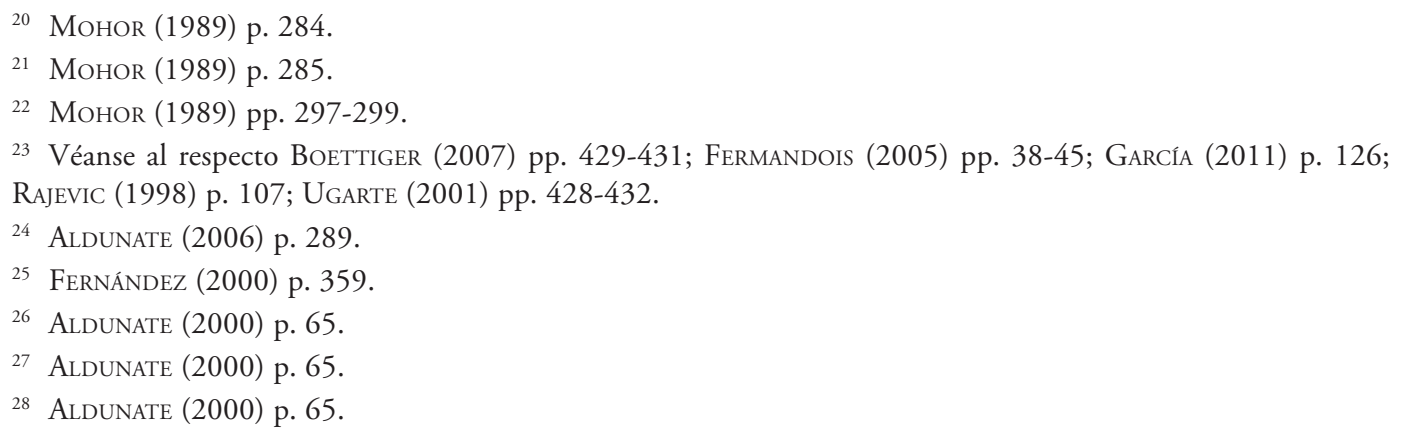


orden a indemnizar las consecuencias económicas desfavorables derivadas de la imposición de cargas públicas, existen paralelamente reacciones críticas ante el potencial expansivo de tales propuestas. Asimismo, se aprecia una tendencia hacia el desplazamiento conceptual, pero ya no mediante la subsunción de la noción de carga pública en la de daño, sino en las de tributo o de limitación. Por fin, en ningún caso parece reconocérsele funcionalidad o utilidad práctica significativa.

Así pues, debe concluirse que no existe una definición precisa y categórica de carga pública que opere como factor de exclusión conceptual o que dé cuenta de su valor instrumental. Sin perjuicio de lo expresado, tomando en cuenta que una cantidad considerable de fallos del Tribunal Constitucional chileno discurre en torno a esta noción y a las garantías que rodean a su imposición, esta conclusión amerita cuestionamiento. Corresponde, por tanto, examinar los pronunciamientos de esta judicatura a objeto de esclarecer el sentido propio y diferenciado que se atribuye a las cargas públicas, así como su función teórica en la argumentación constitucional.

\section{CARACTERIZACIÓN DE LAS CARGAS PÚBLICAS EN LOS FALLOS DEL TRIBUNAL CONSTITUCIONAL}

En numerosas oportunidades el Tribunal Constitucional ha calificado una medida sometida a su control como una carga pública o ha considerado que resultan aplicables las garantías constitucionales asociadas al reparto de esta clase de figuras. No obstante, es relativamente infrecuente que sus pronunciamientos se destinen a determinar en forma explícita qué es una carga pública, cómo esta se diferencia de otras categorías y cuál es la función dogmática que desempeña. En todo caso, esto no impide que puedan encontrarse ciertos considerandos que -aunque fragmentarios e incluso contradictorios entre sí- puedan arrojar ciertas luces sobre la noción de carga pública que maneja esta autoridad.

A modo de ejemplo, puede mencionarse un fallo que explica cómo, en sus orígenes históricos, la reserva legal tributaria estaba íntimamente ligada a la soberanía nacional. Precisamente ese antecedente histórico permite aseverar que el Congreso Nacional representa la instancia más apropiada para que los ciudadanos "discutan e impongan libremente las cargas públicas patrimoniales, entre ellas, ciertamente, los tributos" ${ }^{29}$. Es así como, en esta oportunidad, el Tribunal considera que las cargas públicas constituyen el género al cual pertenece la especie de los tributos. Sin embargo, en otra ocasión ha llegado a la conclusión opuesta, tomando en cuenta los antecedentes de la Carta Fundamental: "la Constitución de 1980 reemplazó las palabras 'impuestos y contribuciones' que empleaba la Carta de 1925 por el vocablo 'tributos', para dejar en claro que este es genérico y que se comprende en él toda exacción patrimonial impuesta por el Estado a las personas para alcanzar el bien común que constituye el fin que le es propio" ${ }^{30}$.

Por otro lado, esta magistratura también ha manifestado, a propósito del término "gravamen especial", empleado en el artículo 19 No 22 de la Constitución, que con él se

29 Roles No 759 (2007) c. $21 ; 733$ (2007) c. $21 ; 718$ (2007) c. 21.

30 Rol No 1063 (2008) c. 96. 
alude a medidas desfavorables impuestas directamente por el legislador o indirectamente por este, autorizando a la administración para su adopción. Estas medidas desfavorables deben ser soportadas "por todo particular que se desenvuelve en un sector económico determinado, a favor del Estado o de otro particular, sin que conlleve una indemnización. Comprende cualquier limitación al dominio, y no se limita solo a las cargas públicas reales o a los tributos" ${ }^{\prime 1}$. Aquí, a diferencia de los dos casos anteriores, tributos y cargas públicas se miran como dos especies de actuaciones estatales que no se vinculan entre sí por la subsunción de una respecto de la otra, sino por su pertenencia a la categoría general de gravámenes especiales. Nótese, además, que esta última expresión se hace sinónima de "medida desfavorable".

Para complicar todavía más las cosas, el Tribunal igualmente ha señalado que las cargas públicas se insertan dentro de un amplio conjunto de deberes que vinculan al individuo con el resto de la colectividad y con el Estado. De allí que la Constitución las trate conjuntamente con los tributos. Tanto aquellas como estos representan obligaciones jurídicamente exigibles y corresponden a la "categoría de compromisos que se vinculan con el bien común de la sociedad"32. Desde esta perspectiva, tributos y cargas públicas pertenecerían a un mismo género superior, que deja de ser el de gravámenes especiales y pasa a ser el de deberes públicos.

Como puede observarse en los considerandos transcritos, replicando el mismo patrón que se presenta en doctrina, existen algunos elementos claves necesarios para aproximarse a un concepto de carga pública. Para empezar, las cargas públicas deben ser creadas y distribuidas por una autoridad estatal. Este es el elemento que dota de índole pública a las cargas. A continuación, la imposición de estas exige un proceso de deliberación pública que posibilite la adecuada y oportuna ponderación de los múltiples intereses comprometidos. Por eso es que se concluye que la autoridad idónea al efecto es el legislador. Y, en último término, ellas deben orientarse al bien común y a la satisfacción de fines de interés general; he allí su fuente de licitud o legitimidad. Empero, "la licitud de los fines perseguidos por el legislador no justifica ni puede permitir el empleo de medios gravosos y desproporcionados"33.

De todas maneras, estos elementos claves son insuficientes para definir la noción de carga pública. No bastan para establecer con precisión su sentido y, a su vez, diferenciarla con nitidez de otras con las que aparece implicada, como las de tributo, gravamen especial, medida desfavorable, deber público y limitación. El problema se agudiza, por lo demás, porque esas otras figuras tampoco poseen un significado inequívoco ni son susceptibles de aislamiento conceptual absoluto ${ }^{34}$. Ciertamente existen algunos factores de distinción,

\footnotetext{
31 Rol No 1295 (2009) c. 91.

32 Rol No 2489 (2014) c. 10.

33 Roles $\mathrm{N}^{\text {os }} 1254$ (2009) c. 75 ; 1140 (2008) c. 43; 1138 (2008) c. 49; 755 (2007) c. 53.

34 Por ejemplo, en relación con los deberes públicos no solo hay discusión en torno la nomenclatura adecuada para referir a estas figuras -deberes constitucionales, deberes fundamentales, deberes aludidos por la constitución-, sino también en cuanto a su obligatoriedad y a su naturaleza jurídica. Una buena relación de estos tópicos desde la perspectiva del derecho español puede verse en Rubio (2001) y Varela (1992). Respecto del concepto de limitación, por su parte, destacan como aspectos controvertidos la distinción entre este y nociones
} 
como la identificación sectorial o local propia de los gravámenes especiales, o como la certidumbre distintiva del daño. Pero esos factores de distinción coexisten con ámbitos de yuxtaposición, habida cuenta que una carga pública supone una disminución obligatoria de la esfera patrimonial y de libertad del particular, en beneficio de la colectividad. Y, a la luz de este prisma, una carga pública podría ser calificada simultáneamente como un deber público o como una limitación.

Incluso así, admitir la inexistencia de una fórmula conceptual monosémica y plenamente depurada dentro de la que se pueda encuadrar la noción de carga pública es una cuestión totalmente distinta a admitir la irrelevancia jurídica de la misma. Tal conclusión contraría el texto fundamental y no se condice con las prácticas del Tribunal Constitucional. Ante este escenario, la cuestión a dilucidar no es cómo se define una carga pública, sino cómo opera esta y cuáles son las consecuencias jurídicas en que se traduce el calificar a un determinado fenómeno como tal. Este enfoque alternativo -funcional, por oposición a otro de carácter formal o analítico- es más flexible y se adapta de mejor modo al carácter omnicomprensivo de la figura en comento, que abarca en sí realidades sumamente heterogéneas y variables.

El siguiente paso a seguir, entonces, consiste en determinar de los criterios empleados por el Tribunal juzga la legitimidad de las cargas públicas. Con este proceder se espera reconocer expresiones de su operatividad que permitan apreciar su función en el ordenamiento jurídico.

\section{DISTINCIÓN ENTRE CARGAS PÚBLICAS REALES Y PERSONALES}

El punto de partida para juzgar la legitimidad de las cargas públicas está dado por la determinación de su carácter personal o real, dependiendo de la naturaleza de la obligación que impone. Al respecto, el Tribunal ha indicado que las cargas públicas pueden ser de dos tipos: "personales, cuando importan el ejercicio obligatorio de una actividad que se impone a la persona por el ordenamiento jurídico, o reales, cuando suponen una afectación patrimonial que también debe ser soportada obligatoriamente por la persona, como las multas o sanciones en dinero que imponen las autoridades dotadas de potestades fiscalizadoras" 35 .

Se trata de una distinción de gran relevancia práctica, pues los requisitos conforme a los cuales debe enjuiciarse la validez de unas u otras es diferente, según se explicará en este apartado.

Por lo que respecta a las cargas personales, esta magistratura las caracteriza -siguiendo a Miguel Marienhoff- como prestaciones impuestas y reglamentadas por ley, de carácter

como la de restricción, delimitación, regulación o privación; la existencia y determinación de límites generales a los derechos fundamentales; y, los límites que, a su vez, se imponen a la limitación de derechos. Para una síntesis del estado de la cuestión en el derecho nacional y español, consúltese Aldunate (2008) pp. 232 ss. Algo similar sucede respecto de los tributos; solo como muestra de ello, en la doctrina nacional hay autores que consideran que el elemento decisivo para calificar a un tributo como tal es la existencia de desplazamiento patrimonial, mientras que otros creen más relevante el valor pecuniario de la prestación objeto de gravamen. Sobre el particular, véase supra, apartado 2.

35 Rol No 1141 (2009) c. 38. 
temporal, de igual aplicación a las personas, irredimibles por dinero, intransferibles, que consisten en servicios ciertos y determinados ${ }^{36}$. En consecuencia, el primer paso en orden a afirmar la constitucionalidad de esta clase de cargas, supondrá verificar la concurrencia de cada uno de estos caracteres. Con todo, el análisis no termina ahí. Adicionalmente, ellas están sujetas a una estricta consideración en cuanto a su gratuidad, pudiendo esta ser objetada (como ha ocurrido en el caso del turno para los abogados) o siendo establecida la exigencia de una compensación (como en la hipótesis del servicio militar obligatorio, las funciones de los vocales de mesas receptoras de sufragios, las funciones del personal de la Oficina Electoral de cada Junta Electoral o las funciones de los miembros de los colegios escrutadores).

En cuanto a las cargas públicas de carácter real, estas son concebidas por el Tribunal fundamentalmente como restricciones a la propiedad. En este sentido, ha identificado como expresiones de tal especie de cargas: la franja televisiva electoral ${ }^{37}$; la exigencia de que medios de comunicación social publiquen o difundan hechos u opiniones que no han sido objeto de noticia, cada vez que terceros consideren que dichos hechos u opiniones tienen importancia o trascendencia social ${ }^{38}$; las limitaciones al urbanizador para destinar y donar gratuitamente terrenos para áreas verdes y equipamiento comunitario ${ }^{39}$; el cambio del precio de un contrato que pasa de libre a regulado ${ }^{40}$; los tributos ${ }^{41}$; las limitaciones a propietarios ribereños para permitir el acceso a las playas ${ }^{42}$; el pago de la atención de accidentes en actos de servicio que sufran los bomberos y que recae en las compañías de seguros ${ }^{43}$; el traslado de instalaciones en las fajas adyacentes a caminos públicos que deben soportar las empresas concesionarias de servicios eléctricos ${ }^{44}$ o el deber de compensar a usuarios de servicios eléctricos por paralizaciones en el suministro ${ }^{45}$. Ellas pueden ser legitimadas aun a pesar de su gratuidad, pero conforme a criterios distintos a los empleados para las cargas personales, según se verá a propósito del test de mesura y razonabilidad.

Así entonces, el criterio interpretativo desarrollado por el Tribunal consiste en que la consideración o ponderación de las cargas personales resulta más severa que la de las cargas reales ${ }^{46}$. En consecuencia, el examen de constitucionalidad de las cargas personales se encuentra sujeto a un estándar de constitucionalidad más elevado, en comparación con el estándar aplicable al examen de las cargas reales. Lo anterior significa abandonar la idea según la cual la distinción entre una clase de carga y otra reside únicamente en su objeto, mas no en el estatuto constitucional aplicable. Pues bien, la pregunta que naturalmente surge

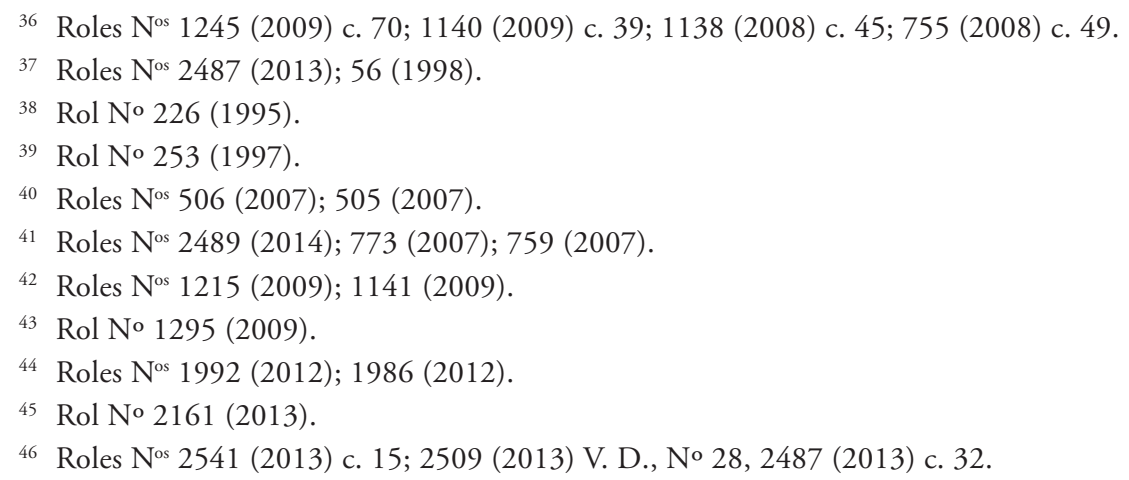


frente a esta distinción es: ¿cómo se justifica el tratamiento diferenciado que se dispensa a cada categoría de carga?

Aunque el Tribunal no es explícito en cuanto a su inspiración, su proceder parece a justarse perfectamente a la naturaleza y a las particularidades de cada modalidad de gravamen, así como a los preceptos constitucionales aplicables a cada uno de ellos.

Recuérdese que, en teoría, las cargas personales suponen la prestación de un servicio o el ejercicio de una función en forma obligatoria y gratuita. Por otro lado, también es necesario tener presente que la Constitución reconoce el derecho de toda persona a la libre contratación y a la libre elección del trabajo con una justa retribución. Y, finalmente, conviene considerar que incluso las funciones más típicamente reconocibles como cargas públicas personales - como las funciones de los vocales de mesa, entre otras-, gozan hoy en día de algún tipo de retribución. De este modo, en la práctica, la regla general es que todo trabajo debe ser remunerado. El solo hecho de que ese trabajo sea desempeñado en cumplimiento de una carga legal no permite, sin más, hacer excepción a esta regla. Para ello será menester superar un estándar de justificación particularmente elevado.

Por lo tocante a las cargas públicas reales, el diverso tratamiento que se les asigna no obedece a una diferencia en cuanto a su entidad. Ellas forman parte del marco normativo aplicable a determinados bienes o actividades. Pero no debe olvidarse que ese marco normativo no solo está integrado por normas que imponen restricciones o gravámenes; también contempla beneficios y privilegios. Tales beneficios y privilegios, en mayor o menor grado, morigeran el impacto económico que la carga puede tener para el titular afectado. Por lo demás, la Constitución prevé expresamente hipótesis de afectación de la propiedad fundadas en su función social o de regulación de las actividades económicas, sin contemplar el pago de una indemnización en contrapartida. Todo ello conduce a la conclusión de que el estándar de justificación de la medida es menor que en el caso anterior.

Los apartados que siguen son destinados al desarrollo de estas ideas.

\section{MESURA Y RAZONABILIDAD DE LAS CARGAS PÚBLICAS}

Una vez determinada la naturaleza real o personal de la carga, el Tribunal se enfoca en precisar cuál es la razón que ha existido detrás de su imposición. Para ello se vale de lo que denomina 'el test de lo mesurado y de lo razonable', como mecanismo de control de la motivación de los actos de la autoridad. Al efecto, los factores relevantes para determinar si el establecimiento de una carga pública es justificado, razonable y no arbitrario han sido sistematizados en la sentencia rol $\mathrm{N}^{\circ} 2541$, sin perjuicio de encontrarse diseminados en una serie de otras sentencias. En ellas, se incluyen factores cualitativos y cuantitativos de análisis, así como criterios relativos a la fuente de imposición de las cargas. Todos ellos son analizados a continuación.

5.1. En relación con la fuente de la carga, el Tribunal reconoce que la identificación de las razones en que se funda la imposición legislativa de una carga presenta tres dificultades. En primer lugar, ellos no están explicitados en la ley misma y, por lo tanto, deben buscarse en otras fuentes: "Ello puede hacerse en la historia de la norma, es decir, en el mensa- 
je o moción, en la discusión en sala o comisión, en los informes de comisión. Esto tiene el inconveniente de que un argumento puede no expresar más que la opinión de uno o más parlamentarios, pero no la del Congreso. De ahí la máxima prudencia que debe haber al escudriñar y determinar estos motivos" ${ }^{47}$.

En segundo lugar, los motivos originalmente considerados como legítimos por el legislador pueden quedar desfasados en el tiempo: "Eso obliga a quienquiera examinar la justificación de una ley, a mirar otros factores de corrección que permitan una adecuación a la época en que la norma se aplica, como puede ser su inserción normativa y la visión sistémica del ordenamiento jurídico. De lo contrario, se produciría una petrificación, un predominio del legislador originario" 48 .

Y, en tercer y último lugar, el control de dichos motivos puede erigirse en un mecanismo de censura de las razones del legislador. En consecuencia el control del Tribunal "consiste [...] en examinar si estos parámetros existen, es decir, que puedan ser detectados; en determinar si son suficientes y si son coherentes con la regulación que se estableció; y señalar si son legítimos" ${ }^{49}$.

5.2. Cuestión distinta es la determinación del vínculo existente entre la razonabilidad, la medida impugnada y la naturaleza del órgano que la adopta. De este modo, una medida impuesta por un órgano de carácter técnico, autónomo y plural, tendría más posibilidades de superar este test que una impuesta por un órgano cuya actuación es definida por el gobierno de turno. Con todo, esta afirmación puede verse matizada en cuanto la medida pudiese emanar de la intervención técnica de un órgano de carácter político, particularmente si actúa en conjunto con otros entes públicos. Conforme a estas consideraciones se ha sentenciado que la carga de transmisión de campañas de utilidad e interés público que pende sobre los canales de televisión abierta es ajustada a la Constitución. Esto es así aun cuando dichas campañas sean diseñadas y elaboradas por el Ministerio Secretaría General de Gobierno, toda vez que en su intervención este actúa como órgano técnico y no actúa unilateralmente ${ }^{50}$.

5.3. Como tercera cuestión, y desde un punto de vista cualitativo, la razón que subyace a la creación de la carga debe poseer sustento y ser legítima. Así, conforme a este factor el Tribunal ha sostenido que la imposición de una carga pública es razonable en dos supuestos: (i) si persigue la concreción o realización de la función pública del bien o derecho regulado o (ii) si contribuye a impedir la desnaturalización de otros bienes o derechos. Por consiguiente, no puede fundarse en una argumentación absurda o caprichosa.

En aplicación de este criterio, se ha resuelto que es legítima la carga que se impone a los propietarios de terrenos colindantes con playas de mar, ríos o lagos, consistente en facilitar gratuitamente el acceso a ellas, por las siguientes razones: "Para acceder a una playa de

\footnotetext{
47 Rol No 1295 (2007) c. 96.

48 Rol No 1295 (2007) c. 96.

49 Rol No 1295 (2007) c. 96.

50 Rol No 2541 (2013) c. 25 y 49.
} 
mar y usar de ella solo es posible hacerlo por aire, mar o tierra. Las vías de acceso marítimo y aéreo se encuentran reservadas a aquellos que puedan hacer uso de medios de transporte que permitan desplazarse a su través, los que son bienes escasos y, por lo general, caros o difíciles de usar. Por ello, el acceso terrestre es, por lo general, el único que permite que un bien reservado a la nación toda sea efectivamente susceptible de 'uso público', pues ello exige de un razonablemente fácil acceso, que solo lo brinda - por lo general- el ingreso terrestre" 51 .

En consecuencia, el gravamen impuesto no solamente es un medio idóneo para garantizar el acceso y uso efectivo de las playas, "sino que puede afirmarse que es un medio necesario del que se vale el legislador para que un bien nacional sea efectivamente de uso público" 52 .

También mediante el recurso a este criterio, se ha declarado que es lícito al legislador modificar el monto del peaje que las concesionarias de servicios eléctricos deben pagar por el uso de redes de transmisión eléctrica. Efectivamente "habiéndose transformado, por decisión legislativa, su negocio en un servicio de utilidad pública que debe soportar una serie de cargas consiguientes, resulta equitativo que se le apliquen, simultáneamente, los precios fijados por la autoridad en virtud de las nuevas condiciones determinadas por la misma ley" 53 .

Por el contrario, en un voto disidente al fallo dictado en el control de constitucionalidad del proyecto de ley sobre el sistema de elecciones primarias, se estimó que en esta clase de elecciones no era razonable la carga de desempeñarse obligatoriamente como vocal de mesa. Las razones que pudieran haberse atendido al legitimar esta carga en elecciones ordinarias, a juicio de los disidentes, no habrían podido replicarse para esta hipótesis, "por tratarse de elecciones [...] restringidas al quehacer de uno o más partidos políticos, cuya existencia está fundada en la libertad de asociación, asegurada por el numeral 15 del artículo 19 de la Constitución, que garantiza que nadie puede ser obligado a pertenecer a una asociación ni, consecuentemente, a trabajar para el cumplimiento de sus fines" ${ }^{54}$.

5.4. De otro lado, esa razón debe ser completa, suficiente y coherente con la finalidad que se persigue con la regulación sometida a control. A la inversa entonces, la razón no puede ser parcial, insuficiente o incoherente. Respecto de este punto, cabe señalar como ejemplo el caso de la carga que se impone a los concesionarios de servicios eléctricos consistente en compensar a usuarios afectados por interrupciones del suministro eléctrico. Dado que la norma impugnada no distinguía según el origen de la interrupción, las concesionarias alegaron que la exigencia de compensación solo resultaría razonable si esta obedeciera a fallas de las instalaciones bajo su administración y cuidado. Contrariamente, resultaría irrazonable si obedeciera a actos u omisiones atribuibles a las empresas eléctricas de transporte o de generación, mas no a deficiencias propias. Frente a tal argumentación, el Tribunal legitimó la carga, señalando que ella "se asienta en la lógica de unos usuarios que no están jurídicamente obligados a perseguir a los terceros responsables, respecto de una prestación

\footnotetext{
51 Rol No 1215 (2009) c. 24.

52 Rol No 1215 (2009) c. 24

53 Roles Nos 506 (2007) c. 33; 505 (2007) c. 33.

54 Rol No 2324 (2012) V. D. de los Ministros señores Marcelo Venegas Palacios y Hernán Vodanovic Schnake.
} 
para cuya cobertura han debido entenderse con un único e impuesto proveedor, que funge como cocontratante" 55 .

A mayor abundamiento: "considerando el carácter vital e imprescindible que reviste para los usuarios finales el normal abastecimiento y disposición de energía eléctrica, es que las consiguientes obligaciones de dar suministro y de mantener la continuidad del servicio público sin desconexiones, se radican a su respecto en las concesionarias de distribución" 56 .

Así las cosas, esta carga no constituye sino una forma de garantizar la prestación continuada e ininterrumpida de servicios eléctricos, cuyas tarifas son previstas para ese propósito $^{57}$. Y, por lo demás, la concesionaria no sufre un perjuicio, pues nada obsta al ejercicio del derecho que le asiste de repetir en contra de terceros responsables ${ }^{58}$.

5.5. Adicionalmente, el Tribunal agrega que el peso argumentativo de que goce la razón invocada por el legislador -en atención a su sustento, a su completitud, suficiencia y coherencia- puede verse reforzado en la medida que esa misma razón haya sido invocada previamente, por su propia jurisprudencia, para legitimar una determinada regulación. Tal es el caso del argumento empleado para legitimar nuevamente la propaganda electoral, pero ahora en elecciones primarias presidenciales, conforme a la cual el uso exclusivo y gratuito de un bien nacional de uso público, como el espectro radioeléctrico, justifica la imposición de cargas sobre los canales de televisión de libre recepción. En dicha sentencia, haciendo referencia a la sentencia rol No 56 se afirmó: "En esa ocasión se presentó una serie de objeciones a dicho mecanismo. En la oportunidad este Tribunal descartó dichas alegaciones, validando la existencia de la franja electoral sobre la base de sostener que la televisión tenía una titularidad restringida en nuestro sistema [...], cumplía una función pública [...] y que la televisión pública abierta tenía ciertos privilegios que no tenía el resto de los medios"59.

5.6. Por otra parte, y ahora desde un punto de vista cuantitativo, se hace presente que no es necesario que exista una batería de argumentos que dé soporte a la medida; no se precisa más que uno solo que satisfaga los criterios antes expuestos. Basta, en consecuencia, con un solo argumento que posea sustento y que sea completo, suficiente y coherente ${ }^{60}$. Inversamente, debiera concluirse que un conjunto de razones carentes de sustento, incompletas, insuficientes e incoherentes no necesariamente servirá para afirmar la razonabilidad de la medida objetada. En consecuencia, la fuerza de la justificación que se presente para legitimar una carga dependerá exclusivamente de su solidez y pertinencia, mas no de su número, ni del solo hecho de que dicha justificación actúe individualmente o en combinación con otras justificaciones.

\footnotetext{
5 Rol No 2161 (2013) c. 10.

56 Rol No 2161 (2013) c. 12.

57 Rol No 2161 (2013) c. 16.

58 Rol No 2161 (2013) c. 18 a 20.

59 Rol No 2161 (2013) c. 18.

60 Rol No 2541 (2013) c. 43.
} 
De esta suerte, el Tribunal ha desarrollado una serie de criterios para la aplicación del test de razonabilidad y cuyo empleo queda de manifiesto en varias sentencias. Se trata de criterios meramente formales, en cuanto reflejan exigencias relativas a las características de los motivos en que se funda la imposición de cargas públicas, sin que provean orientación material alguna respecto de los casos en que puede considerarse que una razón es legítima o posee sustento. No obstante, cuando el test de razonabilidad es proyectado a la gratuidad de las cargas públicas sí es posible reconocer algunas orientaciones sustantivas que sirven de guía a la actividad del Tribunal. A ello se destinarán los dos apartados que siguen, en los que se analizará separadamente el control de la gratuidad de las cargas personales y el control de la gratuidad de las cargas reales.

\section{RAZONABILIDAD Y NO ARBITRARIEDAD DE LA GRATUIDAD DE LAS CARGAS PERSONALES}

Si bien el examen de razonabilidad puede enderezarse a identificar y evaluar las razones o motivos en que se funda la imposición de una determinada carga, en otros casos este examen apunta a establecer si las razones que se alegan para fundamentar un tratamiento legislativo diferenciado son arbitrarias o no; de ahí que, en ocasiones, se le vincule con la garantía de igualdad ante la ley ${ }^{61}$. Sobre el particular el Tribunal Constitucional ha subrayado: "la garantía jurídica de la igualdad supone, entonces, la diferenciación razonable entre quienes no se encuentren en la misma condición; pues no se impide que la legislación contemple en forma distinta situaciones diferentes, siempre que la discriminación no sea arbitraria ni responda a un propósito de hostilidad contra determinada persona o grupo de personas, o importe indebido favor o privilegio personal o de grupo, debiendo quedar suficientemente claro que el legislador, en ejercicio de sus potestades, puede establecer regímenes especiales, diferenciados y desiguales siempre que ello no revista el carácter de arbitrario" 62 .

Tratándose de cargas personales, el test de la razonabilidad de las discriminaciones del legislador adquiere un cariz especial. En este caso, está específicamente encaminado a determinar si hay motivos fundados que justifiquen que ciertas categorías de individuos no reciban una retribución a cambio de un trabajo que, dicho sea de paso, es obligatorio. Ahora bien, para justificar un distanciamiento tan abierto de las reglas generales, se requeriría de una razón particularmente poderosa. Y no bastaría la sola importancia de los derechos o bienes constitucionales que se pretende satisfacer mediante la imposición de la carga. Sostener lo opuesto implicaría reducir la garantía de igualdad ante la ley al mero cumplimiento de fines constitucionalmente legítimos ${ }^{63}$.

61 Sobre la conexión entre igualdad y razonabilidad, así como los cánones de lógica que de acuerdo con este último deben observarse, véanse Bernal (2007) p. 695; Ruiz (1996) pp. 50 ss.; Jiménez (1983) pp. 86 ss.

62 Rol No 986 (2008) c. 32.

63 Para que el fundamento de una desigualdad sea razonable, y no arbitrario, "es preciso que se persiga un fin constitucionalmente lícito, pero esto no es suficiente". Una vez establecido que el fin es lícito, es preciso examinar la diferencia como tal, porque de otro modo el principio de igualdad significaría tan solo que no se pueden per- 
Una buena muestra del modo en que estas ideas cobran aplicación puede observarse en los fallos relativos al turno gratuito de los abogados. En ellos no se desconocía que el propósito perseguido - procurar asistencia y defensa jurídica gratuita para quienes carecen de medios para litigar- era plenamente ajustado a la Constitución. Lo que se cuestionaba era que el criterio de discriminación, la profesión de abogado, justificara privar a quienes la desempeñan del derecho a una justa retribución por su servicio profesional.

Así, en una oportunidad, ante la analogía que se pretendía establecer entre aquellos y los médicos que "para acceder a sus especializaciones deben servir en el sistema de salud pública a cambio de remuneraciones muy inferiores a las que perciben en el ámbito privado" ${ }^{64}$, la refutación del Tribunal se expresó en los siguientes términos: "En efecto, los médicos [...] optan por acceder a una especialización, trabajando en el sistema de salud pública, reciben una remuneración a cambio, en circunstancias que los abogados, que deben desempeñar la carga de asistir gratuitamente a los menesterosos, no reciben compensación pecuniaria por su trabajo ni acceden a una especialidad o beneficio alguno" ${ }^{65}$.

En otra ocasión se llegó a idéntica conclusión, pero estableciendo la comparación con otras cargas, también reconocidas como personales por el Tribunal. Desde este punto de vista, se hizo presente "la situación de desigualdad en que se encontrarían los abogados de turno respecto de otras cargas públicas, como lo son el servicio militar y el actuar como vocal de mesa en un proceso electoral, las que incluso se remuneran actualmente por el Fisco" ${ }^{66}$. Si a todo esto se suma que el Estado cuenta con otros abogados que también proporcionan servicios de asistencia jurídica gratuita a quienes carecen de recursos, a cambio de una remuneración, lo irrazonable de la distinción se torna inconcuso. Recuérdese que en materia penal la defensa jurídica "se efectúa a través de una institución estatal, por sí misma o vía licitación a privados, a quienes, obviamente, se remunera por sus servicios profesionales en conformidad a las bases respectivas ${ }^{67}$.

Fuera de estos casos, desconozco la existencia de otros pronunciamientos en que se enjuicie la legitimidad de la gratuidad de cargas personales. Es probable que ello se deba, justamente, a que el legislador ya ha dispuesto una contraprestación a cambio del cumplimiento de las cargas personales más habituales, mencionadas en el párrafo precedente. En relación con este punto el Tribunal ha sostenido: "Que si bien tradicionalmente se ha entendido que este tipo de cargas personales, en principio, deben ser gratuitas, no es menos cierto que 'ocasionalmente la ley puede establecer algún viático o remuneración' (Néstor Sagüés [...]). En muchos casos también existe compensación por los gastos de cargo del Estado. De manera que si bien la carga pública es gratuita, esta característica 'no es óbice para que el Estado indemnice (presuntivamente) mediante un pequeño emolumento al que cumple la carga' (Rafael Bielsa [...]). En nuestro país, Silva Cimma ha señalado que tratándose de deberes personales, 'jurídicamente, en principio, el derecho a la remuneración no

seguir fines constitucionalmente ilícitos, para lo cual es innecesaria la formulación del principio como tal”. DE Отто (2010) p. 1438.

64 Rol No 1138 (2008) c. 21.

65 Rol No 1138 (2008) c. 25.

66 Roles $N^{\text {os }} 1254$ (2009) c. 43; 1140 (2009) c. 15.

67 Rol 1254 (2009) c. 53. 
puede discutirse y ha sido reconocido en términos más teóricos que reales, pero respetando el principio del derecho administrativo de que toda función pública da origen a una remuneración' ([...])" 68 .

En este estado de cosas, la gratuidad de las cargas personales difícilmente podría legitimarse, a menos que quien esté obligado a soportarla obtenga algún otro tipo de beneficio directo a cambio de su cumplimiento. De no ser así, es de esperar que la comparación entre los sujetos gravados y el resto de los individuos arroje como resultado una discriminación arbitraria. Como lo revela el caso del turno de los abogados, aunque la situación de unos y otros no sea plenamente coincidente o existan algunas diferencias de circunstancias, dichas diferencias "deben considerarse irrelevantes para el disfrute o ejercicio de determinados derechos o para la aplicación de una misma reglamentación normativa" ${ }^{69}$. Dentro de esta tesitura, el test de razonabilidad de las discriminaciones del legislador termina por convertirse en mecanismo de equilibrio entre los intereses públicos encarnados en la imposición de la carga y los intereses privados de quienes deben cumplirla. En las hipótesis reseñadas ese equilibrio se logra únicamente mediante una remuneración dineraria a favor del particular gravado. De cualquier modo, no parece quedar descartada la posibilidad de que pudiera lograrse mediante otro tipo de beneficios o retribuciones no pecuniarias.

Lo que aparece implícito en este esquema argumentativo, es un principio de justicia distributiva que exige ventajas compensatorias a cambio de todo sacrificio que conlleve una prestación o servicio particular para la consecución del bien común. Conforme a este principio, parece negarse que la disminución de las libertades de algunos pueda ser legitimada por el solo hecho de perseguir un fin lícito de interés de toda la colectividad, a menos que esa disminución opere a cambio de una recompensa. Y, paralelamente, parece negarse la posibilidad de que esa recompensa pueda identificarse con las meras ventajas que ofrece la vida en sociedad.

\section{MESURA Y RAZONABILIDAD DE LA GRATUIDAD DE LAS CARGAS REALES}

Un escenario distinto al anterior se presenta cuando se trata de legitimar la gratuidad de las cargas reales. En este caso, no se trata de enjuiciar la razonabilidad de las diferencias de trato que puedan presentarse en la imposición de una carga pública. Se trata de determinar si el hecho de que no se prevea una indemnización o retribución a cambio de soportarla es razonable, sin necesariamente considerarla situación comparativa de otros titulares que deban soportar gravámenes semejantes. Desde esta perspectiva, el test de la mesura y razonabilidad de la gratuidad de las cargas reales focaliza su atención en la carga misma, así como en el balance entre sus consecuencias económicas desfavorables y sus consecuencias favorables para la sociedad o para el propio destinatario de la carga. En concordancia con

68 Roles $N^{\text {os }} 1254$ (2009) c. 73; 1140 (2009) c. 41; 1138 (2008) c. 47; 755 (2008) c. 51. Referencias omitidas.

69 Desde esta perspectiva, la igualdad ante la ley debe entenderse como una exigencia de equiparación. Cfr. Pérez (2007) p. 24. 
PONCE DE LEÓn Solís, Viviana — "La noción de carga pública y su función en la jurisprudencia..."

las sentencias que enuncian formalmente las etapas de este test $t^{70}$, los criterios a considerar para tal efecto son los que se indican a continuación:

7.1. Un primer factor consiste en establecer si la carga impuesta permite concretizar o hacer efectiva la función pública del bien o de la actividad objeto de gravamen. Él constituye una variante de uno de los criterios de justificación de las cargas públicas reseñados previamente, proyectado específicamente a la gratuidad de las cargas reales ${ }^{71}$. Por su aplicación, las cargas que se impongan sobre un título habilitante del uso privativo de un bien nacional de uso público, deben ser soportadas gratuitamente por su titular. Aquí la gratuidad es la contrapartida al privilegio de aprovechar en forma exclusiva un bien que, en principio, podría ser usado por todos.

En este sentido, se ha resuelto que la obligación de emitir propaganda electoral que incumbe los canales de televisión de libre recepción se justifica por el hecho de que "los canales de televisión cumplen una verdadera función de utilidad pública"72. De lo anterior se sigue que: "la norma que contempla el derecho a establecer, operar y mantener canales de televisión e implícitamente a imponerles obligaciones justas y razonables, como es la gratuidad, guarda perfecta armonía con el deber del Estado de asegurar una participación equitativa e igualitaria del pueblo en los plebiscitos y elecciones el cual, a través de estos procesos, ejerce la soberanía"73.

Análogas consideraciones se han reproducido para afirmar la legitimidad de la obligación de los canales de televisión de libre recepción de transmitir propaganda electoral para las elecciones primarias presidenciales ${ }^{74}$.

7.2. La segunda variable a tomar en cuenta, supone determinar si existen privilegios que compensen el gravamen impuesto. Entonces, si dentro del marco normativo aplicable al sujeto gravado con la carga se contemplan estatutos especiales, más favorables que los aplicables al resto de los individuos, se entiende justificada la imposición de la carga. Conforme a estas ideas, se ha decidido que es ajustada a la Constitución la carga a que se sujetan los canales de televisión abierta, consistente en transmitir campañas de utilidad e interés público. Para ello, el Tribunal ha tenido presente que los canales de televisión están sujetos a un estatuto privilegiado: "usan un bien nacional de uso público con sus concesiones. También, tienen derecho a las servidumbres que sean necesarias para operar y mantener sus estaciones [...] Y, los actuales concesionarios de libre recepción respecto de la televisión digital, mantienen sus concesiones analógicas [...] y tienen el derecho de solicitar una nueva concesión de radiodifusión televisiva digital [...] sin someterse a concurso, para lo cual el Estado debe reservar espectro radioeléctrico”75.

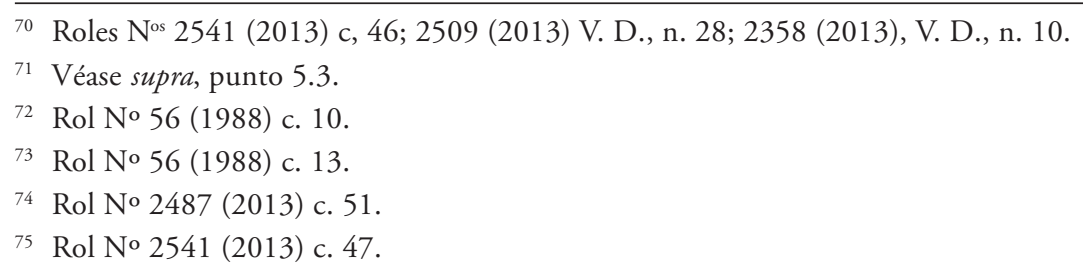


Este razonamiento ha sido igualmente empleado para resolver acerca de la constitucionalidad de la carga que se impone a las concesionarias de servicios básicos, consistente en costear el traslado de sus instalaciones ubicadas en las fajas adyacentes a caminos públicos. Sobre el particular se ha sostenido: "Que no se advierte razón que justifique que quienes ocupan dichas fajas gratuitamente, no tengan la limitación de soportar el costo de un traslado de sus instalaciones. La pregunta es por qué no van a tener estas restricciones, si una serie de otros sujetos, para garantizar el libre tránsito por los caminos, sufre restricciones a sus derechos"76.

Semejante conclusión se sustenta el hecho de que "el concesionario puede usar gratuitamente y de modo exclusivo, un pedazo de un bien nacional de uso público, un bien que es de todos y que, de no mediar el permiso, podrían usar todos"77 y por el hecho de que "[t]odas las otras instalaciones que ocupen la faja, después de 1996, deben pagar por ello"78.

7.3. Como último elemento a considerar, es necesario precisar si existen beneficios que compensen el gravamen impuesto. De este modo, las ventajas o utilidades que deriven del uso del bien gravado o del ejercicio de la actividad gravada en cierta medida neutralizan los efectos patrimoniales de la carga, legitimando consiguientemente su gratuidad. Es así como, una vez más a propósito del traslado de fajas adyacentes, se ha fundado la constitucionalidad de la carga de traslado en el hecho de que la respectiva concesionaria goza de "una suerte de monopolio natural en la zona de concesión [...]; puede disponer de servidumbres en terrenos privados [...]; cobra una tarifa que le asegura una rentabilidad económica mínima [...] y que deben pagar todos los usuarios, sin excepción”79.

La misma idea subyace a la sentencia sobre los aportes que las compañías aseguradoras deben realizar a favor de los bomberos. En ese pronunciamiento el Tribunal aseveró que: "los bomberos intervienen, por una parte, previniendo incendios. Ellos deben informar las condiciones de seguridad de ciertas construcciones, para evitar siniestros. Por la otra, actúan apagando incendios, o sea, bajando el costo de lo que la Compañía debe pagar al asegurado. Además informan de las causas del incendio, contribuyendo a determinar si hubo o no hecho de la víctima, de terceros o de la naturaleza en el daño producido, y ayudando de este modo a determinar cuál es el monto a pagar por la Compañía"80.

De esta manera, la actividad bomberil beneficia a las aseguradoras, lo cual justifica la carga que se impone a estas.

Finalmente, este criterio también ha sido utilizado para legitimar las cesiones de terrenos que se urbanicen conforme a las disposiciones de Ley General de Urbanismo y Construcciones y su ordenanza. Respecto a dichas cesiones, se ha indicado que: "lejos de constituir un daño patrimonial para el dueño procura un beneficio pecuniario para él, pues el valor de los terrenos urbanizados, es superior al valor de dichos terrenos sin urbanizar,

\footnotetext{
76 Rol No 1992 (2012) c. 56.

77 Rol No 1992 (2012) c. 59.

78 Rol No 1986 (2012) c. 51.

79 Rol No 1992 (2012) c. 59.

80 Rol No 1295 (2009) c. 98.
} 
incluyendo por cierto, en este último, los costos que demanda la urbanización tanto por la ejecución de las obras respectivas como aquellos que derivan de la pérdida de superficie por las cesiones gratuitas" $"$.

En fin, a la luz de la revisión de estos tres criterios quedan en evidencia diferencias significativas entre el examen de la gratuidad de las cargas personales y el examen de la gratuidad de las cargas reales. En efecto, para determinar si la gratuidad de una carga personal es razonable o mesurada, es necesario comparar la situación del sujeto gravado con la situación de otras categorías de sujetos gravados. Si solo algunas categorías soportan la carga a cambio de una retribución y otras no, entonces es necesario determinar si ese trato diferenciado se encuentra justificado. Por ende, la razonabilidad de la gratuidad de las cargas personales es guiada por un principio de igualdad. Al contrario, para determinar si la gratuidad de una carga real es razonable o mesurada es necesario considerar el modo en que se articula el interés público que motiva la imposición de la carga, con los intereses privados del titular afectado por ella. Se sigue de lo señalado que si existe un cierto equilibrio o compensación entre unos intereses y otros, la imposición de la carga debe estimarse justificada. Aquí la lógica subyacente no es de igualdad ${ }^{82}$, sino de justicia.

Más allá de esta diferencia, puede constatarse que el examen de gratuidad de las cargas reales también recoge un principio de justicia distributiva, según el cual se exigen ventajas compensatorias a cambio de todo sacrificio que incida en el patrimonio de un individuo, para la consecución del bien común. Eso sí, en este caso se explicita que dichas ventajas compensatorias no necesariamente deben traducirse en una suma de dinero. Con base en estas observaciones, cabe sostener que la noción de carga pública, en cualquiera de sus dos modalidades, opera como fundamento de una exigencia de equilibrio o balance a favor del particular que soporta un gravamen en beneficio de toda la colectividad.

Por otro lado, en virtud de este razonamiento, surge una alternativa de tratamiento para los efectos patrimoniales desfavorables que puede acarrear la imposición de cargas reales, cuyo foco ya no está exclusivamente situado en la indemnización de perjuicios, sino en un balance más amplio entre contribuciones particulares y ventajas sociales ${ }^{83}$. De esta manera, es posible atender los intereses particulares involucrados en la regulación, sin comprometer recursos estatales limitados que pudieran destinarse a la satisfacción de diversos fines

\footnotetext{
81 Rol No 253 (1997) c. 10.

82 De hecho, los cuestionamientos a la gratuidad de las cargas públicas reales fundados en un tratamiento desigual suelen ser desechados por el Tribunal. En esta línea de pensamiento pueden verse los Roles Nos 1234 (2008) c. 10 y 16; 790 (2007) c. 37 a 39.

83 En la jurisprudencia norteamericana sobre las regulaciones expropiatorias -íntimamente vinculada a la noción de carga pública, según se expuso más arriba- se presenta este mismo fenómeno, con sustento en la idea de average reciprocity of advantage. De acuerdo con esta idea, una limitación a la propiedad puede estimarse legitimada si, recíprocamente, el titular gravado obtiene algún beneficio que compense la carga que soporta. Una primera consecuencia práctica que deriva de la recepción de esta idea es que disminuyen significativamente las posibilidades de objetar con éxito la constitucionalidad de la limitación. Cfr. WadE y Bunting (2007); Ball y Reynolds (2006) pp. 1536 ss.; Coletta (1990) p. 302. Como segunda consecuencia de la recepción de esta idea, se introducen en la argumentación constitucional consideraciones de justicia distributiva, del mismo modo en que lo he sostenido para el caso chileno. Cfr. Durden (2013) pp. 46-48; Dagan (1999).
} 
de interés común ${ }^{84}$. Por último, pese que el Tribunal parece admitir la indemnizabilidad de ciertas cargas reales ${ }^{85}$, esta nueva aproximación se concilia de mejor manera con la jurisprudencia de la Corte Suprema, quien en los últimos años ha rechazado reiteradamente la procedencia de acciones indemnizatorias por supuestas vulneraciones a las garantías del artículo 19 No $20^{86}$.

\section{PROPORCIONALIDAD DE LAS CARGAS PÚBLICAS}

Por lo usual, el juicio acerca de la razonabilidad de la gratuidad de las cargas públicas resulta decisivo en el examen de la proporcionalidad de estas. De esta forma, si la gratuidad de la carga es irrazonable, al mismo tiempo la carga será innecesaria y desproporcionada. En contraste, si la gratuidad de la carga es razonable, el grado de sacrificio que ella representa para el derecho afectado se verá moderado o equilibrado por las ventajas o compensaciones que reciba su titular. Visto así el asunto, la razonabilidad de la gratuidad de las cargas públicas constituye un canon particularmente relevante para enjuiciar la legitimidad de estas. Para ilustrar este punto me remito a un par de ejemplos.

8.1. Ya se ha dicho que, aparte del fallo sobre la gratuidad del turno de los abogados, no existen otros pronunciamientos relevantes acerca de la constitucionalidad de las cargas personales gratuitas. De todos modos, de llegar a suscitarse un caso en el futuro, lo más probable es que se resuelva con una sentencia que declare la inaplicabilidad o la inconstitucionalidad de la medida, según el caso. Lo estimo así porque, como he señalado antes, es muy difícil que se determine que la gratuidad de una carga personal es razonable. En efecto, la comparación con otras categorías de sujetos que prestan servicios profesionales o que realizan prestaciones forzosas con fines de bien común siempre arrojará como resultado que la regla general es la retribución de dichos servicios o prestaciones.

Lo anterior tiene un profundo impacto en el control de proporcionalidad de las cargas personales. Por más que se constate la razonabilidad del gravamen en sí mismo o su idoneidad para satisfacer los fines de interés públicos pretendidos, la falta de razonabilidad de su gratuidad impedirá que la medida pueda considerarse necesaria y proporcionada en sentido estricto. Ante múltiples ejemplos de servicios similares remunerados -sea en cumplimiento de una carga legal o no-, forzoso es concluir que siempre existiría una medida alternativa, igualmente eficaz para alcanzar el fin propuesto, pero menos lesiva para el derecho afectado. Esa medida alternativa perfectamente podría ser la misma carga sometida a control, pero a cambio de una contraprestación. De no ser así, ella se revela a sí misma

\footnotetext{
84 En relación con esta problemática y otras derivadas de una concepción expansiva de las cargas públicas y de su indemnizabilidad, véase Aldunate (2000).

85 Roles Nos 2299 (2014) c. 9; 1215 (2009) c. 37 y 38; 1141 (2009) c. 33 y 34.

86 Esta magistratura ha sostenido que se incurre en un error al invocar una vulneración a la garantía de igualdad ante las cargas públicas como fuente de la responsabilidad del Estado, puesto que "no hay normativa que consagre la pretendida obligación indemnizatoria por infracción a los artículos 19 No 20 y No 24 de la Constitución Política”. Véase la sentencia de la Corte Suprema, Rol No 8079 (2013) c. 16. Otros pronunciamientos de semejante tenor pueden hallarse en los roles $N^{\text {os }} 9924$ (2012) c. 14 y 15; 381 (2004) c. 51.
} 
como excesivamente gravosa o desproporcionada. En palabras del Tribunal: "el fin perseguido por el legislador de dar asistencia jurídica gratuita no solo resulta constitucionalmente lícito sino también debido. Por su parte, el instrumento, consistente en establecer una carga, es idóneo para cumplir dichos fines. Sin embargo, si se impone gratuitamente, se transforma irremediablemente en un medio desproporcionadamente gravoso, desde el momento que el fin perseguido no exige ni supone que el abogado deba desempeñarse sin retribución alguna. Y ello, porque la obligación se radica en el Estado y no en los abogados. El Estado, entonces, puede satisfacerla transfiriéndola a los abogados (bajo el sistema de defensorías e incluso del turno, como en la especie), pero no es necesario ni lícito desde un punto de vista constitucional que se les imponga sin retribución" ${ }^{87}$.

8.2. En el caso de las cargas reales, también es posible advertir que el juicio acerca de la razonabilidad de su gratuidad tiene incidencia en el examen de su proporcionalidad, particularmente a nivel de proporcionalidad stricto sensu. Al respecto, el Tribunal ha expuesto que las cargas públicas pueden estimarse proporcionadas siempre que no importen privación. Esto significa que, por más elevado que sea el grado de satisfacción de otros derechos o bienes constitucionales que se alcanza con la imposición de la carga, esta ha de considerarse ilícita si conlleva una privación de la propiedad del sujeto gravado. En sentido opuesto, las cargas reales que importen un grado de restricción que no pueda calificarse como privación, han de estimarse como legítimas y ajustadas a la Carta Fundamental.

Inmediatamente, este razonamiento hace surgir la pregunta acerca de cuáles son los supuestos en que una carga real deviene en una privación. Al efecto, en los fallos constitucionales se han definido tres criterios: (i) una carga constituye una auténtica privación cuando existe desplazamiento patrimonial, esto es, cuando el bien sobre el cual recae la carga no permanece en el patrimonio de su titular ${ }^{88}$; (ii) ello también ocurre cuando la medida afecta el núcleo o contenido esencial del derecho, vale decir, cuando la carga no deje subsistentes las facultades de uso, goce y disposición del particular gravado con ella ${ }^{89}$; , asimismo, (iii) cuando la carga ocasione daños innecesarios o imponga gravámenes de magnitud considerable ${ }^{90}$. A su vez, esta hipótesis tendrá lugar, cuando ponga en peligro las utilidades del titular afectado, cuando su imposición genere costes adicionales de producción o cuando entorpezca la actividad regulada hasta hacerla inviable por excesiva onerosidad.

En las hipótesis (i) y (ii) se está en presencia de una genuina privación de la propiedad, en los términos del artículo 19 No 24 inciso $3^{\circ}$ de la Constitución. No es, por tanto, la falta de proporcionalidad de la carga lo que determinará su ilicitud, sino derechamente la inobservancia de la garantía expropiatoria. Inversamente, en la hipótesis (iii) el principio de proporcionalidad sí es la herramienta adecuada para determinar el grado admisible de pérdidas, costes u onerosidad que debe soportar la propiedad, en atención a la importancia de los fines de interés público que se pretende lograr. El punto es que si, conforme al test de

\footnotetext{
87 Rol 1254 (2009) c. 65.

88 Roles $\mathrm{N}^{\text {os }} 2299$ (2014) c. 8; 1992 (2012) c. 60; 1986 (2012) c. 60.

${ }^{89}$ Roles $N^{\text {os }} 2299$ (2014) c. 22; 2451 (2009) c. $48 ; 1141$ (2009) c. 21; 246 (1996) c. 23; 245 (1996) c. 22 , 23 y 25.

90 Roles Nos 2487 (2013) c. 44; 2451 (2013) c. 48; 1669 (2012) c. 87.
} 
razonabilidad de la gratuidad de las cargas reales, se establece que existen suficientes beneficios y privilegios que equilibren o compensen la limitación, entonces tendrá que concluirse que la medida no es desproporcionada. Y, en este sentido, la razonabilidad de la gratuidad de la carga casi invariablemente excluirá su ilegitimidad. Por lo menos así ha ocurrido en los últimos siete años ${ }^{91}$.

El principio de proporcionalidad, frecuentemente "entendido como un principio formal a partir del cual no se deriva ningún contenido material para el control de constitucionalidad" 92 , aparece ahora guiado por un criterio sustantivo. Entonces, para resolver si la carga es "equilibrada por derivarse de aquella más beneficios o ventajas para el interés general que perjuicios sobre otros bienes, valores o bienes en conflicto, en particular sobre los derechos y libertades" 93 , habrá que atender a lo que se resuelva respecto de su gratuidad. Al tenor de lo señalado, en la medida que exista algún tipo de ventaja o compensación en favor del afectado -que no necesariamente se traducirá en una retribución pecuniaria- podrá afirmarse que se alcanza un equilibrio entre ventajas para el interés general y perjuicios para los bienes, valores, libertades y derechos individuales afectados. Este es el criterio en función del cual se asigna el peso relativo de los intereses involucrados al desarrollar el test de proporcionalidad; otras apreciaciones empíricas que, en teoría, pudiera el Tribunal tener a bien considerar no suelen ser determinantes.

\section{CONCLUSIONES}

1. En el último tiempo, la noción de carga pública ha concitado un gran interés académico y jurisprudencial. Ello podría atribuirse a que la generalidad de las construcciones teóricas desarrolladas para proteger los derechos de los individuos frente a los efectos negativos derivados de la actividad estatal lícita tiende a articularse en torno a la noción de carga pública. No obstante, dado que dichas construcciones pueden terminar por constreñir en forma excesiva actuaciones estatales deseables y necesarias, en la literatura comparada sobre este tema surge de modo reiterado una preocupación por acotar el sentido de la expresión carga pública. Las propuestas en tal sentido apuntan a reconocer como elementos esenciales de esta noción: su origen en un acto estatal legítimo, la ponderación previa de los intereses públicos y privados concernidos en su imposición, y su orientación a la consecución del bien común.

2. A nivel local, esta noción también ha atraído la atención de la doctrina, en términos similares a los antes expuestos. La diferencia radica en que, contando con una norma constitucional que autoriza expresamente al Congreso para imponer cargas públicas, el principal punto a esclarecer pasa a ser la naturaleza jurídica de estas y su relación con otras

\footnotetext{
${ }_{91}$ El precedente sentado en los fallos roles $N^{o s} 505$ (2007) y 506 (2007) es crucial en esta materia. Desde entonces, el Tribunal reconoce que la magnitud o intensidad de las cargas que se imponen a la propiedad no es indiferente, pero suele legitimarlas conforme al principio de razonabilidad y de proporcionalidad.

92 Gavara de Cara (1994) p. 310. Adhieren a este planteamiento, entendiendo al principio de proporcionalidad como un principio formal, procedimental o argumentativo, Bernal (2007) pp. 196-199; Prieto (2007) p. 118; Medina (1998) p. 131.

${ }^{93}$ Barnés (1994) p. 500.
} 
categorías dogmáticas. Por el momento, las soluciones ofrecidas no son del todo satisfactorias, observándose una clara tendencia hacia la subsunción conceptual. Lo mismo ocurre en los pronunciamientos del Tribunal Constitucional; aunque identifican como componentes estructurales de la noción de carga pública los mismos elementos que señala la doctrina, no logran definir con exactitud su sentido ni su posición respecto de otras figuras.

3. En ausencia de una definición formal, esta investigación propone indagar en el sentido instrumental o a la función que desempeña la noción de carga pública en la argumentación constitucional. En los fallos sobre el particular aparece como tópico recurrente la idea de balance o equilibrio entre el sacrificio que experimenta el sujeto que cumple la carga y el beneficio que ello representa para la comunidad. En el caso de las cargas personales, ese equilibrio usualmente se expresa en una indemnización o en una retribución pecuniaria en favor de quien soporta el gravamen. En cambio, en el caso de las cargas reales, lo corriente será que ese equilibrio que se proyecte en una suerte de compensación que opera entre aquellas y otros beneficios o privilegios que puedan moderar su impacto económico. Desde esta perspectiva, la noción de carga pública opera como un vehículo para introducir consideraciones de justicia distributiva en la argumentación constitucional.

4. Tales consideraciones, que son decisivas en el examen de razonabilidad de la gratuidad de las cargas públicas, se ven reafirmadas en el juicio de proporcionalidad, en sus sucesivas y ya conocidas etapas de idoneidad, necesidad y proporcionalidad en sentido estricto. Ellas ya no solo operarán como guías procedimentales o metodológicas de la argumentación del juez constitucional, sino que estarán orientadas por un criterio sustantivo: un principio de justicia distributiva consistente en que todo sacrificio de la libertad o los derechos de los particulares debe ser compensado. Por consiguiente, los argumentos y las apreciaciones empíricas que suelen ser tomadas en cuenta en su desarrollo, son las que permiten dar por establecida la existencia de alguna forma de compensación. Lo anterior demuestra que la función propia y distintiva de la noción de carga pública en los fallos del Tribunal Constitucional chileno es fundar una exigencia de equilibrio entre el interés público y privado, que solo puede satisfacerse mediante algún tipo de compensación.

\section{BIBLIOGRAFÍA CITADA}

Aldunate Lizana, Eduardo (2008): Derechos Fundamentales (Santiago, LegalPublishing).

Aldunate Lizana, Eduardo (2006): "Limitación y expropiación: Scilla y Caribdis de la dogmática constitucional de la propiedad”, Revista Chilena de Derecho, vol. 33 No 2: pp. 285-303.

Aldunate Lizana, Eduardo (2000): "Consecuencias constitucionales de la doctrina sobre responsabilidad objetiva del Estado”, Revista de Derecho Consejo de Defensa del Estado, vol. 1 No 2: pp. 61-78.

Ball, Carlos A. y Reynolds, Laurie (2006): "Exactions and burden distribution in takings law", William and Mary Law Review, vol. 47 No 5: pp. 1513-1585.

BARNÉS VÁSQUEZ, Javier (1994): "Introducción al principio de proporcionalidad en el derecho comparado y comunitario", Revista de Administración Pública, No 135: pp. 495-535. 
Bernal Pulido, Carlos (2007): El principio de proporcionalidad y los derechos fundamentales (Madrid, Centro de Estudios Políticos y Constitucionales).

Boettiger Philipps, Camila (2007): "Regulación del Estado con fines sociales en material urbanística: ¿̇limitación a la propiedad, impuestos o cargas públicas?”, XXXVII Jornadas Chilenas de Derecho Público, volumen II (Valparaíso, Pontificia Universidad Católica de Valparaíso): pp. 415-435.

Chapus, René (2001): Droit administratif generale I (París, Montchrestien).

Cianciardo, Juan (2004): El principio de razonabilidad. Del debido proceso sustantivo al moderno juicio de proporcionalidad (Buenos Aires, Editorial Ábaco de Rodolfo de Palma).

Coletta, Raymond R. (1990): "Reciprocity of advantage and regulatory takings: toward a new theory of takings jurisprudence", The American University Law Review, vol. 40: pp. 297-366.

Dagan, Hanoch (1999): “Takings and distributive justice", Virginia Law Review, vol. 85 No 5: pp. 741-804.

De Otto y Pardo, Ignacio (2010): "Igualdad", en De Otto y Pardo, Ignacio, Obras completas (Madrid, Centro de Estudios Políticos y Constitucionales) pp. 1437-1444.

Delvolvé, Pierre (1969): Le principed'égalité devant les charges publiques (París, Librairie Generale de Droit et de Jurisprudence).

Durden, Stephen (2013): "Unprincipled principles: the takings clause exemplar", Alabama Civil Rights \& Civil Liberties Law Review, vol. 3 No 2: pp. 25-68.

Fermandois Vöhringer, Arturo (2005): "Inaplicabilidad de la Ley de Monumentos Nacionales: hacia la inconstitucionalidad de la expropiación regulatoria en Chile, Inmobiliaria Maullín Ltda. con Fisco de Chile. Inaplicabilidad, Rol 4309-2002, 18 de junio de 2002”, en Fermandois Vöhringer, Arturo (edit.), Sentencias Destacadas 2004. Una mirada desde la perspectiva de las politicas públicas (Santiago, Libertad y Desarrollo) pp. 19-53.

Fernández González, Miguel Ángel (2000): "Principios constitucionales de proporcionalidad y justicia en materia tributaria”, Revista Chilena de Derecho, vol. 27 No 2: pp. 357-371.

Gaba, Jeffrey M. (2007): “Taking 'fairness and justice' seriously: distributive justice and the takings clause”, Creighton Law Review, vol. 40 No 3: pp. 569-594.

García García, José Francisco (2011): “El Tribunal Constitucional y el uso de 'tests': una metodología necesaria para fortalecer la revisión judicial económica”, Revista Chilena de Derecho, vol. 38 No 1: pp. 101-138.

Gavara de CARA, Juan Carlos (1994): Derechos fundamentales y desarrollo legislativo. La garantía del contenido esencial de los derechos fundamentales en la Ley Fundamental de Bonn (Madrid, Centro de Estudios Constitucionales).

Jiménez Campos, Javier (1983): "La igualdad jurídica como límite frente al legislador", Revista Española de Derecho Constitucional, vol. 3 No 9: pp. 71-114.

LiERMAN, Steven (2013): "Law as a complex adaptive system: the importance of convergence in a multi-layered legal order”. Disponible en: http://www.rechten.unimaas.nl/ iuscommune/activities/2013/2013-11-28/plenair_Lierman.pdf. 
Martínez, José Ignacio y Zúñiga Urbina, Francisco (2011): “El principio de razonabilidad en la jurisprudencia del Tribunal Constitucional”, Estudios Constitucionales, vol. 9 No 1: pp. 199-226.

Medina Guerrero, Manuel (1998): "El principio de proporcionalidad y el legislador de los derechos fundamentales", Cuadernos de Derecho Público, No 5: pp. 119-141.

Meillon, Dimitri (2006): "Un nouveau fondement pour la responsabilité sans faute des personnes publiques: la garded'autrui”, Revue du Droit Public et de la Science Politique, vol. 122 No 5: pp. 1221-1246.

Mir Puigpelat, Oriol (2002): La responsabilidad patrimonial de la Administración. Hacia un sistema de responsabilidad (Madrid, Civitas).

Mohor Abuauad, Salvador (1989): "Taxonomía de las limitaciones al dominio y derecho de indemnización”, Revista Chilena de Derecho, No 16: pp. 283-308.

Pérez Luño, Antonio Enrique (2007): Dimensiones de la igualdad (Madrid, Dykinson) 135 pp.

Philipp, Dominique (1999): "De la responsabilité à la solidarité des personnes publiques", Revue du droit public et de la Science Politique, vol. 2: pp. 593-631.

Rajevic Mosler, Enrique Petar (1998): "La propiedad privada y los derechos adquiridos ante la planificación urbana", Revista Chilena de Derecho, vol. 25 No 1: pp. 65-112.

Rubio Llorente, Francisco (2001): "Los deberes constitucionales", Revista Española de Derecho Constitucional, vol. 21 No 62: pp. 11-56.

Ruiz Miguel, Alfonso (1996): "La igualdad en la jurisprudencia del Tribunal Constitucional", Doxa. Cuadernos de Filosofía del Derecho, vol. 19: pp. 39-86.

TJepkema, Michiel (2010): Nadeelcompensatie op basis van het égalitébeginsel : een onderzoek naar national, Frans en Europees recht (Leyden, Kluwer International Law) 1.065 pp.

Ugarte Godoy, José Joaquín (2001): "Limitaciones al dominio. De las meras restricciones y de cuándo dan lugar a indemnización”, Revista Chilena de Derecho, vol. 23 No 2: pp. 425-448.

Varela Díaz, Santiago (1992): "La idea de deber constitucional”, Revista Española de Derecho Constitucional, vol. 2 No 4: pp. 69-96.

Venezia, J. C. (1975): "The protection of equality in French public law", en Koopmas, T. (edit.), Constitutional protection of equality (Leyden, Sijthoff) pp. 125-158.

WAdE, William W. y Bunting, Robert L. (2007): "Average reciprocity of advantage: 'magic words' or economic reality - lessons from Palazzolo", The Urban Lawyer, vol. 39 No 2: pp. 319-370.

\section{JURISPRUDENCIA CITADA}

\section{Corte Suprema de Chile}

UnIVERSidAd de MAGALLANES CON SERVICIO AgRíCOLA Y GANADERo (2013): Sentencia rol No 8079-2010, de 8 de abril de 2013 (recurso de casación en el fondo).

Productos Fernández S.A. con Ministerio de SALUd (2012): Sentencia rol No 9924-2010, de 20 de noviembre de 2012 (recurso de casación en el fondo).

Sociedad Agrícola Lolco Ltda. con Fisco (2004): Sentencia rol No 381-2004, de 30 de diciembre de 2004 (recurso de casación en el fondo). 
2. Corte Suprema de Estados Unidos

Agins v. City of Tiburon, 447 U.S. 255(1980).

ARMstrong V. UNITED StATES, 364 U.S. 40 (1960).

\section{Tribunal Constitucional de Chile}

Sentencia rol No 2489-13-INA, de 15 de abril de 2014.

Sentencia rol No 2299-12-INA, de 29 de enero de 2014.

Sentencia rol No 2541-13-CPT, de 18 de noviembre de 2013.

Sentencia rol No 2509-12-INA, de 24 de septiembre de 2013.

Sentencia rol No 2487-13-CPR, de 21 de junio de 2013.

Sentencia rol No 2161-12-INA, de 4 de abril de 2013.

Sentencia rol No 2358-12-INA, de 9 de enero de 2013.

Sentencia rol No 1992-11-INA, de 24 de diciembre de 2012.

Sentencia rol No 1986-11-INA, de 24 de diciembre de 2012.

Sentencia rol No 2324-12-CPR, de 20 de noviembre de 2012.

Sentencia rol No 1295-08-INA, de 6 de octubre de 2009.

Sentencia rol No 1234-08-INA, de 7 de julio de 2009.

Sentencia rol No 1215-08-INA, de 30 de abril de 2009.

Sentencia rol No 1141-08-INA, de 17 de marzo de 2009.

Sentencia rol No 1140-08-INA, de 14 de enero de 2009.

Sentencia rol No 1138-08-INA, de 8 de septiembre de 2008.

Sentencia rol No 1063-08-CPR, de 12 de junio de 2008.

Sentencia rol No 755-07, de 30 de marzo de 2008.

Sentencia rol No 790-07, de 11 de diciembre de 2007.

Sentencia rol No 773-07, de 26 de noviembre de 2007.

Sentencia rol No 759-07, de 26 de noviembre de 2007.

Sentencia rol No 718-07, de 26 de noviembre de 2007

Sentencia rol No 506-06, de 6 de marzo de 2007.

Sentencia rol No 505-06, de 6 de marzo de 2007.

Sentencia rol No 253, de 15 de abril de 1997.

Sentencia rol No 226, de 30 de octubre de 1995.

Sentencia rol No 56, de 9 de agosto de 1988. 
